\title{
Levels of lysyl- and arginyl-naphthylamidase in sera of normal and allergic subjects
}

The immediate type allergic reaction in human atopic subjects is generally believed to be initiated by the local union of atopic allergens and reaginic antibody, and the allergen-reagin complex is considered to trigger the sequence of reactions ultimately leading to the release of pharmacologically active substances, $e \cdot g$. histamin, serotonin, and the kinins kallidin-1o (lysyl-bradykinin) and bradykinin. It has been suggested that the failure to inactivate these particular kinins enzymatically might afford one possible explanation of the untoward clinical response reaction to allergens in allergic patients. Tewksbury and Marschke ${ }^{1}$, employing the Schultz-Dale technique for measuring the breakdown of bradykinin added to the sera of normal and ragweedsensitive asthmatic individuals, were unable to detect differences in the level of the kininase between the two groups of sera; Sicuteri $e^{\prime} a{ }^{2}{ }^{2}$ and Watanabe claim opposite results.

A number of enzymes are known to be involved in the biological breakdown of the kinins, viz: carboxypeptidase $\mathrm{N}$, attacking the $\mathrm{C}$-terminal arginine of bradykinin ${ }^{4}$, and aminopeptidase $\mathrm{B}$, cleaving the $\mathrm{N}$-terminal lysine of kallidin-Io but reported incapable of hydrolyzing the $\mathrm{N}$-terminal arginine-prolyl bond of the reaction product, bradykinin ${ }^{5}$. There is some evidence that proteolytic enzymes, presumably activated by the antigen-antibody complex, act upon an $\alpha_{2}$-globulin substrate to form kallidinIo first, which must be converted into bradykinin by aminopeptidase ("converting enzyme") before the pharmacological activity can be completely destroyed". The pos" sible inability of human allergic sera to convert the vaso-active peptide kallidin-ro into the nonapeptide has not yet been taken into consideration as a likely mode of potentiation of the initial allergen-reagin interaction.

METHOD

The specific lysyl- and arginyl-aminopeptidase B in human sera has not yet been well identified. For the present work the level of these enzymes in human sera was established employing the $\beta$-naphthylamides of $L$-lysine and $L$-arginine, as described by Hopsu et al. ${ }^{7}$ for the assay of aminopeptidase B in animal tissues and organs. Presumably, these particular enzymes in blood serum represent isoenzymes of le1cine aminopeptidase; adopting the suggestion of Arturson et al. ${ }^{8}$, they will further be designated serum naphthylamidases. The following procedure was found suitable.

The reaction mixture for the estimation of lysyl- and arginylnaphthylamidases contained $\mp .5 \mathrm{ml}$ Tris(hydroxymethyl)aminomethane-HCl buffer $0.1 M, \mathrm{pH} 7.0,0.2 \mathrm{ml}$ L-lysyl- $\beta$-naphthylamide carbonate or L-arginyl- $\beta$-naphthylamide $\mathrm{HCl}(0.2 \mu$ mole; Mann Res. Labs.), $0.5 \mathrm{ml}$ of dist. water and $50 \mu \mathrm{l}$ of serum. The reaction was allowed to proceed for $60 \mathrm{~min}$ at $37^{\circ}$ and was stopped by the addition of $x \mathrm{ml}$ o.r\% Fast Garnet GBC Salt in I $M$ sodium acetate buffer $\mathrm{pH} 6.5$. After $30 \mathrm{~min}$ at room temperature for full colour development the extinction of the samples was read at $525 \mathrm{~nm}$ in a Unicam SP 600 spectrophotometer against a blank containing all the reagents except the enzyme substrate (same final volume). The calibration curve, constructed with cryst. $\beta$-naphthylamine-HCl, was linear up to o.I $\mu$ mole. 
RESULTS

Normal control sera were obtained from healthy male volunteers, aged between 20-30 years and without apparent symptoms of disease (group I). Allergic sera were drawn from patients of all ages attending the Out-patient Department of Allergy with symptoms of asthma, hay fever, vasomotor rhinitis, urticaria or bacterial allergy (group II). A third group was separated from group II, comprising those individuals with positive immediate type reactions to $0 . \mathrm{I} \mu \mathrm{g}$ of intradermally administered house dust allergen or human dandruff allergen as one criterion of true atopy (group III).

\section{TABLE I}

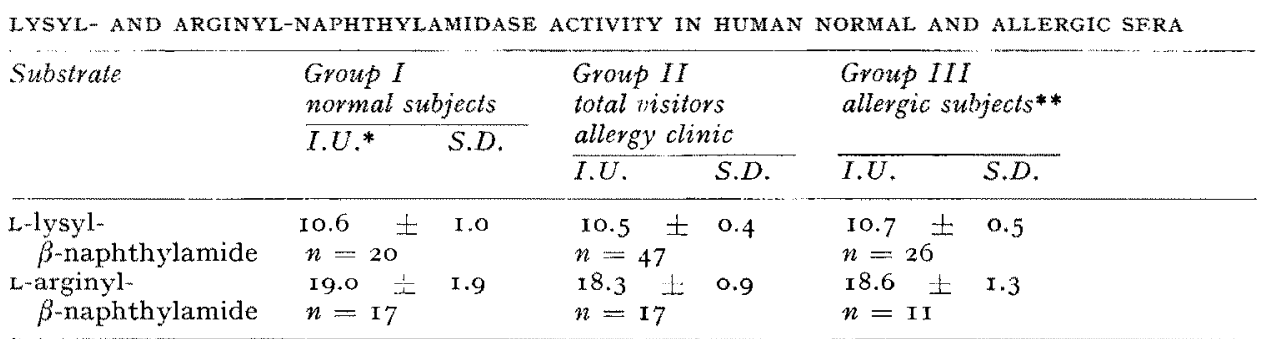

* Values in International Units ( $\mu$ moles/min/l).

** Fositive by skin test to $0.1 \mu$ or of house dust and/or human dandruff allergen.

The results of enzyme assay in these groups of sera have been listed in Table $I$. No significant differences were detected in the level of lysyl-or arginyl-naphthylamidase between the individual groups. The average level of leucyl- $\beta$-naphthylamidase in these sera was established at 32 International Units, in agreement with the values reported by Rockerbie and Rasmussen ${ }^{9}$ and by Fleischer et al. ${ }^{10}$. In consequence, the ratio of leucyl-, arginyl- and lysyl-naphthylamidase activity in human sera is about $32: 19: 10$, or roughly $3: 2: 1$.

\section{DISCUSSION}

It follows from these results that, if the aminopeptidase hydrolyzing the $\mathrm{N}$ terminal lysine of kallidin-ro in human serum is identical to the lysyl-naphthylamidase studied here, no significant differences exist in the ability of sera of normal and allergic individuals to degrade this particular kinin. No evidence exists in the literature for the possible inactivation of bradykinin by an aminopeptidase cleaving the $\mathrm{N}$-terminal arginine-prolyl linkage, but if this were one of the physiological functions of serum arginyl-naphthylamidase, normal and allergic human subjects would also be equally well equipped for the rapid breakdown of the nonapeptide. With respect to the possible impaired breakdown of the kinins two possibilities arise, viz: a diminished level (or complete absence) of the degrading enzyme(s), or a reduced capacity by inhibition. The available evidence is in disfavour of the first possibility; the alternative of inhibited enzymes should be investigated in the presence of allergens. The susceptibility of human serum naphthylamidases to inhibition by atopic allergens will be discussed in a separate paper. 


\section{ACKNOWLEDGEMENTS}

Thanks are due to Drs. N. Mul for submitting a collection of normal sera, to Dr. E. Young for supplying the sera of allergic patients, and to Mrs. W. Nolles-Van Roo for technical assistance.

Department of Dermatology, Section Biochemistry of the Skin, L. BerRens University Hospital, Utrecht (The Netherlands)

I D. A. Tewksbury and G. R. Marschke, Intern. Arch. Allergy, 30 (1966) 538 .

2 F. Srcuteri, M. Fanctullacci and B. Anselmi, Intern. Arch. Allergy, 22 (1963) 77.

3 N. Watanabe, Tohoku J. Exptl. Med., 92 (1967) 63.

4 E. G. ERdös, H. Y. T. Yang, L. L. Tague and N. Manning, Biochem. Phammacol, I6 (1967) 1287 .

5 V. K. Hopsu-Havu, K. K. Mäkinlin AND G. G. GlenNek, Nature, 212 (1966) 1'271.

6 M. E. Webster and J. V. Pierce, Ann. N.Y. Acad. Sci., To4 (rg63) 9 I.

7 V. K. Hopsu, K. K. Mäkinen and G. G. Glenner, Acta Chem. Scand., 20 (1966) r225.

8 G. Arturson, L. Beckman and B. H. Persson, Natwe, 214 (1067) 1252.

9 R. A. Rockerbie and K. L. Rasmussen, Clin. Chim. Acta, 18 (1967) I83.

io G. A. Fleischer, M. Pankow and G. Warmka, Clin. Chim. Acta, $9(1964) 254$.

Revised manuscript received January 10, 1968

Clin. Chim. Acla, $20(1968)$ I70-I72

\section{ERRATA}

Clin. Chim. Acta, vol. I8, p. 249, in the fourth paragraph read:

... "Small amounts of free testosterone have been found...", instead of "Small amounts of testosterone glucuronoside have been found...".

Clin. Chim. Acta, vol. 20, p. 4 (this volume), in TABLE I:

the number of cases against Gargoylism should be $(n=4)$ instead of $(n=14)$. 